\title{
As setas longas do palhaço
}

\author{
Renato Ferracini
}

Um palhaço entra em cena e inicia a relação. $\mathrm{O}$ Estado Cênico ${ }^{1}$ criado nesse momento é infinitamente complexo e todos os elementos que o constroem, podemos dizer, são indiscerníveis. Ele gera, então, uma zona de turbulência, ou poderíamos chamar, também, de zona de jogo, que abarca, num só espaço-tempo, outro e recriado, a atualização da relação poética palhaço-público. Essa relação turbulenta, geneticamente dinâmica, gera uma bolha lírico-poética altamente complexa, que se movimenta em continuum e se torna independente do espaço-tempo cotidiano, atualizando, poderíamos dizer, um espaço-tempo poético. A isso chamamos de forma resumida, fenômeno teatral.
Mas, claramente, não é somente o palhaço que é capaz dessa atualização poética. Atores, performers e dançarinos, obviamente também possuem essa capacidade de atualização. Mas, existiria alguma diferenciação na zona de turbulência gerada pelo palhaço e por outros artistas cênicos dentro dessa bolha lírica e dessa atualização espaço-temporal? Esse artigo busca, de uma forma bastante simplificada, fazer algumas ponderações sobre essa questão.

Poderíamos iniciar dizendo que essa zona de turbulência abrange, ao menos, uma dupla seta (cada ponta uma multiplicidade) dentro de um único vetor. Essas setas afetam o espectador ao mesmo tempo em que os espectadores afetam os atores.

Renato Ferracini é pesquisador do LUME-UNICAMP.

1 Chamo de Estado Cênico o momento específico em que o ator se encontra na ação de atuação juntamente com o público e com todos os elementos que compõe a cena. Prefiro usar o termo "Estado Cênico" ao geralmente usado "Estado de Representação" ou ainda "Representação" pois acredito que o conceito de "representação", mesmo não sendo usado nesse artigo dentro de um território filosófico, pode gerar distorçōes dentro da conceituação do trabalho do ator, já que esse termo possui uma carga conceitual histórica densa e pela massa enorme dessa carga pressionará, certamente, o conceito teatral de "representação" que, dentro do território teatral, pode ser simplesmente pensado enquanto atuação, ação de atuar. Mas devemos esclarecer que o ator não se coloca no lugar de algo, não representa algo. Ele não é uma imagem imperfeita colocada no lugar de uma outra imagem. Ele não é, portanto, uma segunda presença que está no lugar de uma primeira presença que não está ali, seja de uma suposta personagem, seja de uma imagem, seja ainda de um estado emotivo. Na verdade, o ator cria uma ação poética recriada a cada instante no momento em que atua, age em cena. Ele não se coloca no lugar de algo, mas cria um espaço único, uma ação única que gera um acontecimento também único. 
SETA PARA FORA (AFETAR): na construção do corpo-subjétili, ${ }^{2} \mathrm{o}$ ator deveria buscar a possibilidade de abertura das ações, matrizes ${ }^{3}$ ou estados, recriando-os "para fora", transbordando-os para o espaço e para o outro. No LUME, o trabalho pré-expressivo é realizado com esse intuito e alguns exercícios específicos como os Lançamentos e o Fora do Equilíbrio trabalham essa questão. Uma matriz ensimesmada, um estado "fechado" não é capaz de entrar em zona de turbulência. Se a ação não possuir essa seta pra fora, ela acaba permanecendo apenas no âmbito pessoal do ator e, dessa forma, não afeta o espectador. Muitas vezes vemos atores cujas ações físicas no palco parecem levá-lo a um estado de grande intensidade, mas uma intensidade alocada em um universo pessoal. Já presenciei a atuação de atores que até mesmo entram em estado de um suposto "arrebatamento" cênico, mas que não me afetam de forma alguma, nem me lançam em um estado de jogo, vizinhança e turbulência. Se uma matriz ou estado não possui essa seta para fora enquanto vetor de afetação, ela não gera um corpo-subjétil e o Estado Cênico não acontece.

\section{SETA PARA DENTRO (SER AFETA-}

$\mathrm{DO})$ : em realidade, se o ator cria abertura para possibilidades de lançamento de suas matrizes e estados, de uma seta pra fora, se cria zonas de aberturas e porosidade de seu corpo-subjétil,

2 CORPO-SUBJÉTIL: um corpo-em-arte não pode ser conceituado como uma ponta de dualismo, mas como um corpo integrado e vetorial em relação ao corpo com comportamento cotidiano. Chamei, então, esse corpo integrado expandido como corpo-em-arte, esse corpo inserido no Estado Cênico, de corpo-subjétil. Subjétil seria, segundo Derrida, retomando uma suposta palavra inventada por Artaud, a palavra ou a coisa [que] pode tomar o lugar do sujeito ou do objeto, não é nem um, nem outro (Derrida \& Bergstein, 1998, p. 23). Um subjétil não é um sujeito, muito menos o subjetivo, não é tampouco o objeto, mas exatamente o "quê", e a questão do "quê" guarda um sentido no que concerne ao que está entre isto ou aquilo [...] (p. 38; grifo meu). Outra questão é que essa palavra subjétil pode, por semelhança, ser aproximada da palavra projétil, o que nos leva à imagem de projeção, para fora, um projétil que, lançado para fora, atinge o outro e, como ficará mais claro adiante, também se autoatinge. Essa aproximação pode ser realizada já que "subjétil" é uma palavra intraduzível, pois, como foi supostamente inventada por Artaud, não existe tradução possível em outras línguas. Corpo-subjétil: um corpo em Estado Cênico, um corpo em arte, pois encontra-se nesse "entre" objetividade - subjetividade, pois não é nem um nem outro exatamente, mas os perpassa pelo meio, englobando as duas pontas da polaridade e todos os outros pontos que passem por essas linhas opostas. Ele não é um ponto ou outro, uma linha ou outra, mas uma diagonal que atravessa esses pólos abstratos e todos os pontos e linhas "entre". Em segundo lugar, porque esse "entre" do subjétil, agindo como um projétil, lança-se para fora para agrupar e incluir o outro, em um movimento que deveria ser natural no trabalho do ator. Portanto, o corpo-subjétil engloba e diagonaliza um espaço "entre" polaridades que se completam e uma ação que lança esse espaço "entre" para fora, numa relação dinâmica que é, intrinsecamente, o terreno do trabalho do ator.

3 Dentro do âmbito de trabalho do LUME, podemos dizer que uma ação física e/ou vocal orgânica, pesquisada e codificada por um ator e que dinamiza seus campos intensivos potenciais, é chamada de "matriz". Se procurarmos no dicionário Aurélio, encontraremos algumas das razōes para essa palavra ter sido utilizada para definir uma ação física orgânica: "Matriz: lugar de onde se gera ou se cria; aquilo que é fonte, origem, base; útero". Assim, a matriz é entendida como o material inicial, principal e primordial; é como a fonte de material do ator, à qual ele poderá recorrer, sempre que desejar, para a construção de qualquer trabalho cênico. A matriz é a própria ação física/vocal, viva e orgânica, codificada que pode ser recriada no momento do Estado Cênico. Dessa forma, cada ator possui um conjunto de matrizes, que se torna seu vocabulário vivo de comunicação cênica - seu vocabulário expressivo. 
essa mesma abertura dá ao corpo-subjétil a possibilidade de entrada, de ser afetado. É por isso que a zona de turbulência é uma seta dupla em um único vetor. A mesma porosidade que busca afetar, gera a possibilidade de ser afetado. Essa seta é, dentro do possível, segmentada. Quero dizer, com isso, que a seta do "ser afetado" pode ir de curta até muito longa, dependendo da proposta do espetáculo e da proposta de zona de turbulência que pretende criar o corpo-subjétil.

Explico-me com exemplos: nos espetáculos do LUME buscamos gerar uma zona de turbulência, que é variável conforme a proposta de cada espetáculo. Assim, um Cnossos (1995) ou um Kelbilim, o cão da divindade (1988) - que utilizam matrizes (estados e açôes) bastante codificadas, com uma densidade muscular muito grande e, conseqüentemente, com um uso de energia extremada, tudo "amarrado" dentro de uma estrutura espetacular também codificada ao nível de micro ações e impulsos - gera-se zonas de turbulência que não se manifestam na macro mudança visível, nem das matrizes do corposubjétil nem na própria estrutura do espetáculo. Claro que existe uma zona de "ser afetado" no ator, pois há a zona de turbulência geneticamente dinâmica, mas ela acontece em um nível muito pequeno, como desvio de pequenos estados, micro mudanças de ritmos, micro alterações de densidades musculares, percebida, sim, tanto pelo ator quanto pelo público, mas não de maneira macroscópica no nível de matrizes e da estrutura espetacular. Poderíamos dizer que nesses espetáculos há uma seta curta de "ser afetado". Saliento: dizer que há uma "seta curta de ser afetado" não significa dizer, em absoluto, que essa seta seja menos intensa. Setas curtas e longas não possuem qualquer diferença de grau de intensidade no nível das forças virtuais em relação à zona de turbulência, mas apenas diferenças de grau nas conseqüências de modificação no nível da percepção visível, tanto das matrizes, como da estrutura do espetáculo. Qualquer comprimento de seta será intenso dentro da zona de turbulência, mas no caso de uma seta curta as mudanças, as turbulências, são realizadas numa relação quase microscópica no corpo-subjétil do ator.

Nos espetáculos de palhaços ou clowns ${ }^{4}$ temos uma zona de turbulência criada com setas longas de afetar e ser afetado, por dois grandes motivos: em primeiro lugar porque um espetáculo de palhaço é baseado, no nível das ações, em um estado de palhaço e não em matrizes codificadas, ao menos no nível de micro densidades e micro impulsos como em Cnossos (1995) e Kelbilim, o cão da divindade (1988). Não entrarei, aqui, em detalhes dos trabalhos que geram esse estado, pois isso pode ser encontrado em publicaçóes anteriores, mas posso dizer que um estado de palhaço ou de clown (como preferirem!) é a ativação de todos os trabalhos anteriores de palhaço, desde todo o trabalho de iniciação até trabalhos mais técnicos que buscam, dentro desse estado inicial, gerar ações, ampliação dos estados iniciais, pesquisas de modos de relacionamento com o meio e com outros palhaços. ${ }^{5}$ Essa é uma característica do palhaço como trabalhamos dentro do LUME: ele trabalha com um estado, que o leva a agir

4 Não entrarei aqui na tentativa, ao meu ver, hoje, infrutífera, de diferenciação conceitual entre palhaço e clown. Palhaço é clown, clown é palhaço e fim.

5 Para saber mais sobre o processo de iniciação de palhaço e trabalhos técnicos posteriores, dentro da proposta do LUME, ver Burnier, 2001, principalmente o capítulo 8, "O Clown e a improvisação codificada”. Ver, também, em meu livro, $A$ arte de não interpretar como poesia corpórea do ator, o sub-capítulo "O clown", a partir da página 217. Na Revista do LUME, n. 1, ver o artigo "O riso em três tempos", de Ricardo Puccetti. Na Revista do LUME, n. 2, ver o artigo "Caiu na rede é riso", também de Ricardo Puccetti, e na Revista do LUME, n. 3, o artigo "O clown através da máscara", de Ricardo Puccetti. 
dentro de uma lógica própria de relacionamento, gerando, portanto, uma zona de turbulência diretamente vinculada a essa lógica e a esse estado. Justamente essa zona de turbulência, gerada pelo próprio estado do corpo-subjétil (palhaço), é que determina suas ações físicas, que nascem a partir de sua relação com o espaço, com os objetos a seu redor, com os outros palhaços, com seu figurino e principalmente com o público. Claro que há uma codificação de macro ações durante todo o espetáculo, mas elas mesmas podem ser alteradas e modificadas pelas longas setas da zona de turbulência. Assim, dentro do estado de palhaço podemos mesmo criar novas ações e alterar as que já existem, pois as setas do "ser afetado" alcançam, inclusive, o nível das macro-ações. Em segundo lugar porque, mesmo que os espetáculos de palhaço tenham uma linha a ser seguida, ela não é absolutamente rígida, podendo ser rompida a qualquer instante desde que haja alguma relação de jogo com o espaço, com o outro palhaço ou mesmo com o público. A linha dramática desses espetáculos é porosa, fazendo com que o palhaço possa sair e entrar dela sempre que necessário. Por isso, muitas vezes, a sensação de que trata de um espetáculo improvisado, ou de um espetáculo que contém muita improvisação. Mas tomemos cuidado com essa "sensação" de improvisação. Um palhaço improvisa dentro desse estado e dessa zona de turbulência criada pelo próprio corpo-subjétil do ator-palhaço. $\mathrm{O}$ palhaço necessita de muito tempo de treinamento em sala, de relação com o público, de entendimento corpóreo de sua lógica de relacionamento com o universo ao seu redor. Todo esse trabalho gera ações físicas que serão repertoriadas pelo ator. Esse trabalho acumulado (tanto de vivências como de ações físicas) gera punctums na musculatura do corpo. Um estado de palhaço é a ativação de todos esses punctums em um corpo-subjétil aberto para novas ações físicas, e ao improviso com todo seu repertório dentro da zona de turbulência criada por esse mesmo estado de palhaço. E isso não vale ape- nas para o trabalho de palhaço, mas para todo o trabalho de ator.

Em outros espetáculos, como em Café com Queijo (1999), existem setas longas e curtas que se alternam dentro da zona de turbulência criada. Há momentos em que o espetáculo possui codificações absolutamente microscópicas, imprimindo setas curtas na zona de turbulência e outros em que trabalhamos apenas com os estados das matrizes e, portanto alongamos os segmentos das setas na zona de turbulência. Mas independente do tipo de codificação e do alongamento das setas de "ser afetado", é importante colocar que um corpo-subjétil, ao mesmo tempo, cria, habita e é essa zona de turbulência, zona sem a qual o próprio corpo-subjétil seria inexistente.

A existência dessa zona de turbulência em dupla seta, além da necessidade da recriação de uma ação pela impossibilidade de sua mera repetição, acaba gerando uma grande instabilidade no Estado Cênico, fazendo com que um espetáculo nunca seja exatamente igual a outro, por mais absolutamente codificado e amarrado que ele seja. Todo acontecimento teatral é instável em vários níveis dentro de sua aparente estabilidade. Primeiro, uma instabilidade no nível da própria relação entre corpo-subjétil e corpo cotidiano, pois já que uma ação física ou matriz não será repetida mas recriada num continuum zigue-zague com os punctums, a serem ativados no corpo cotidiano, qualquer alteração do "estado momento" do corpo cotidiano (uma forte gripe, febre, um abalo emocional) pode afetar, mais ou menos, a recriação do corposubjétil. Afetando a recriação do corpo-subjétil, afetaremos a criação da própria zona de turbulência, gerando uma instabilidade em segundo nível no próprio corpo-subjétil, já que este cria, gera, afeta e é afetado pela zona de turbulência. Finalmente, essa zona de turbulência, criada e dependente do corpo-subjétil já instável realiza-se pela própria criação de instabilidade no acontecimento teatral, criando, em si, um terceiro nível de instabilidade. Assim, em um pla- 
no espetacular, o corpo-subjétil, ao mesmo tempo gera, habita e é definido pela própria zona de turbulência e possibilita o afetar e o ser afetado pelo espaço, pelo outro ator, e pelo público de uma maneira que jamais se repete. A zona de turbulência é uma zona de forças em relação gerando instabilidades em continuum. E o pa- lhaço é mestre na criação e total implosão dessa zona, recriando-a e reconfigurando-a a todo instante, afinal...

E o palhaço o que é?

É ladrão de mulher.

E o palhaço o que foi?

Ladrão de boi.

\section{Referências bibliográficas}

BURNIER, L. O. A arte de ator: da técnica à representação. Campinas: Editora da Unicamp, 2001.

DERRIDA, J. \& BERGSTEIN, L. Enlouquecer o subjéctil. Trad. de Geraldo Gerson de Souza. São Paulo: Fundação Editora da UNESP, 1998. 